\title{
Investigating the Effect of Skill Related Physical Fitness on the Development of Technical Ability in the Case of Debre Markos University under -17 Male Football Project Players
}

\author{
Abrham Abebe Ferede \\ Research scholar, Debre Markos university, Ethiopia
}

\begin{abstract}
This study aims to investigate the effect of skill related physical fitness on the development of technical ability: in the case of Debre Markos University under-17male Football project players. Explosive leg power, speed, agility physical fitness components and distance accurate shooting and speed dribbling technical components of Football project players were the main target of the study. They were 25 in number but due to injuries 2 players excluded whereas the remaining all 23 players were selected by using purposive sampling method. The average age of the participants' was $16 \pm 0.756$ years. To assess the level of physical and technical components of the player's field test was used. The data was analyzed through multivariate and simple linear regression statistics method. The finding of the study showed that most of the players had very poor level of power performance, excellent level of speed and agility performance when we compared with the international standard of physical fitness level. On average, accurate shooting increased by 3.241 times significantly when explosive leg power increased by 1 meter, On average, speed dribbling was increased by 6.847 second times significantly when speed increased by one second and On average, speed dribbling was increased by 1.628 second times significantly when agility increased by one second. Therefore skill related physical fitness (explosive leg power, speed and agility) had their own effect on the development of technical ability in football.
\end{abstract}

Keywords: -Development, physical fitness, techniques ability and skill related

DOI: $10.7176 / \mathrm{JTHS} / 53-01$

Publication date: January $31^{\text {st }} 2021$

\section{Back ground of the study}

Soccer is one of the most widely played and complex sports in the world, where players need technical, tactical, and physical skills to succeed. Without good physical fitness, players are rarely able to play the game with good technique, (Chapman.et al, 2007). For achieving top results in this sport, it is necessary that players have an exceptionally high level of technical and tactical skills as well as significant physical fitness, (Sevensson\& Drust, 2005).

Fitness in soccer specific context refers to a range of individual characteristics that is a composite of many attributes and competences. Such competence by definition includes, physical, physiological, and psychomotor factors, (Reilly \& Williams, 2003). Physically superior players feel less fatigued during the game played with the same intensity and, therefore, those players experience less decrement in technical performance, (Jukic, et al, 2011).

Modern football requires the player to have high physical abilities has become one of the main pillars in training plan either daily, weekly, seasonally, and annually. Player's abilities significantly increased in the world in the recent years on looking at players now and years ago, we find that their physical abilities have grown in a remarkable way Hanafi (1994). Players in competitive soccer require high levels of power, speed, and agility to perform explosive movements such as heading, shooting, sprinting, and dribbling,(Stolen,et al.,2005). The various codes of football played around the world have much in common in terms of their physical demand and correspondingly the importance of fitness testing (Pyne.etal, 2014).

Technical preparation of football players is the main precondition for efficient motion performance. More precisely, technical preparation enables that motor potential of a soccer player reaches its maximum. We have to stress that further progress in terms of technical improvement of a soccer player is not possible without parallel work development and maintenance of those motor abilities which are vital for the game of football (Smajić, M., Molnar, S., 2007).

The context of this study was on Debre Markos University under-17 male football project players. Debre Markos is found in Ethiopia specifically in Amharal region, the capital city of East Gojjam zonal administration. Debre Markos University under- 17 male football projects is found in Debre Markos city. It was consisted 25 players. This study involves from the total number of 25 trainees only 23 participants were used as a subject but the remaining 2 trainees due to injury were excluded. The specific objectives of this study was to check skill related physical fitness level of Debre Markos University under- 17 male football project players go in line with international test standards, to Evaluate the effect of explosive leg power on distance shooting and to assess is 
the effect of speed and agility on the development of speed dribbling.

\section{Material and method}

Aiming to study the effect of skill related physical fitness on the development of technical ability: in the case of Debre Markos University under-17 male Football project players; this study covers 25 trainees in the age of 1617age groups, who train for football at Winter Sports University. This study involves from the total number of 25 trainees only 23 participants were used as a subject but the remaining 2 trainees due to injury were excluded. Their average age was $16 \pm 0.756$.

All testing candidates underwent a systematic medical examination which is a standard procedure. Therefore, all the testing candidates are healthy and with no visible aberrations that might affect testing results in the research. Before directly engaged to the test the participants were requested to warm up for 12 minutes prior to the test program and cooling- down for 8 minutes following the test program. Standing long jump pre-test was applied to test trainees explosive leg power, 30 meter accelerate run pre- test was applied to test trainees speed ability and Illinois agility run per-test was applied to test their agility abilities. Counting accurate and non-accurate shooting from 30meters distance far from the goal line per- test was applied to measure shooting development and speed dribbling pre- test was applied to test speed dribbling development. For the purpose of this research, and in accordance with the research aim, multivariate linear regression was used to evaluate the effect of explosive leg power on distance accurate shooting and simple linear regression method was used on the effect of speed and agility on speed dribbling abilities.

\section{Results}

Based on the gained data, we can see from Table 1 that on to evaluate explosive leg power physical fitness level of Debre Markos University under- 17 male football project players go in line with international test standards are as follows: - $1(4.3 \%)$ of player was categorized under average level, $2(8.7 \%)$ of players was categorized under below average, $8(34.8 \%)$ of players was categorized under poor level and the remaining $12(52.2 \%)$ of players was categorized under very poor level.

Table 1

\begin{tabular}{|c|c|c|c|}
\hline & & Frequency & Percent \\
\hline \multirow[t]{5}{*}{ Valid } & Average & 1 & 4.3 \\
\hline & Below average & 2 & 8.7 \\
\hline & Poor & 8 & 34.8 \\
\hline & Very poor & 12 & 52.2 \\
\hline & Total & 23 & 100.0 \\
\hline
\end{tabular}

Based on the gained data, we can see from Table 2 that on to evaluate speed physical fitness level of Debre Markos University under- 17 male football project players go in line with international test standards are as follows: $-11(47.8 \%)$ of players was categorized under excellent level, $8(34.8 \%)$ of players was categorized under above average level, $3(13 \%)$ of players was categorized under average level and the remaining $1(4.3 \%)$ player was categorized under below average level.

Table 2

\begin{tabular}{|l|l|l|l|}
\hline \multicolumn{2}{|l|}{} & Frequency & Percent \\
\hline Valid & Excellent & 11 & 47.8 \\
\hline \multirow{5}{*}{} & Above average & 8 & 34.8 \\
\cline { 2 - 4 } & Average & 3 & 13.0 \\
\cline { 2 - 4 } & Below average & 1 & 4.3 \\
\cline { 2 - 4 } & Total & 23 & 100.0 \\
\hline
\end{tabular}

Based on the gained data, we can see from Table 3 that on to evaluate agility physical fitness level of Debre Markos University under- 17 male football project players go in line with international test standards are as follows: - $10(43.5 \%)$ of players categorized under excellent level, 4(17.4\%) of players categorized under above average, $8(34.8 \%)$ of players categorized under average level and the remaining $1(4.3 \%)$ of players categorized under below average.

Table 3

\begin{tabular}{|l|l|l|l|}
\hline \multicolumn{1}{|l|}{ Valid } & Frequency & Percent \\
\cline { 2 - 4 } & Excellent & 10 & 43.5 \\
\cline { 2 - 4 } & above average & 4 & 17.4 \\
\cline { 2 - 4 } & Average & 8 & 34.8 \\
\cline { 2 - 4 } & below average & 1 & 4.3 \\
\hline & Total & 23 & 100.0 \\
\hline
\end{tabular}

Table 4 indicates that On average, accurate shooting increased by 3.241 times significantly when power 
increased by 1 meter on the other hand non-accurate shooting increased by 3.241 times significantly when power decreased by 1 meter.

Table4

\begin{tabular}{|l|l|l|l|l|l|}
\hline \multirow{2}{*}{ Dependent Variable } & & & & & \\
& Parameter & B & Std. Error & t & p-value \\
\hline Accurate & Intercept & -3.364 & 1.623 & -2.072 & .051 \\
\cline { 2 - 7 } & Power & 3.241 & .842 & 3.851 & .001 \\
\hline Non-Accurate & Intercept & 8.364 & 1.623 & 5.152 & .000 \\
\cline { 2 - 6 } & Power & -3.241 & .842 & -3.851 & .001 \\
\hline
\end{tabular}

Table 5 indicates that on average, speed dribbling was increased by 6.847 second times significantly when speed increased by one second.

Table 5

\begin{tabular}{|c|c|c|c|c|c|}
\hline \multirow[b]{2}{*}{ Model } & & \multicolumn{2}{|c|}{ Unstandardized Coefficients } & \multirow[b]{2}{*}{$\mathrm{T}$} & \multirow[b]{2}{*}{$\mathrm{p}$-value } \\
\hline & & $\mathrm{B}$ & Std. Error & & \\
\hline & (Constant) & -4.432 & 2.392 & -1.853 & .078 \\
\hline & Speed & 6.847 & .602 & 11.368 & .000 \\
\hline
\end{tabular}

Table 6 indicates that on average, speed dribbling was increased by 1.628 second times significantly when agility increased by one second.

Table 6

\begin{tabular}{|c|c|c|c|c|c|}
\hline \multirow[b]{2}{*}{ Model } & & \multicolumn{2}{|c|}{ Unstandardized Coefficients } & \multirow[b]{2}{*}{$\mathrm{T}$} & \multirow[b]{2}{*}{ p-value } \\
\hline & & $\mathrm{B}$ & Std. Error & & \\
\hline & (Constant) & -2.993 & 2.946 & -1.016 & .321 \\
\hline & agility & 1.628 & .186 & 8.740 & .000 \\
\hline
\end{tabular}

\section{Discussion}

Depend on multivariate linear regression pre-test statistical data explosive leg power has its own effect on distance accurate shooting because the value of " $\mathrm{P}$ " is 0.001 and trainees who have better explosive leg power, they have better performance to demonstrate distance accurate shooting. Other researchers concluded that Power in its various forms (maximum and explosive power, rate of force development) plays a critical role on performance of such skills (Capri et al., 1988). There for players who have better explosive leg power, they can demonstrate distance accuracy shooting towards the goal. Depend on simple linear regression pre-test statistical data speed and agility has their own effect on speed dribbling because the value of $\mathrm{P}$ is 0 and trainees who have better speed and agility they have better performance to demonstrate speed dribbling. and also it consists by Haghighi et al. (2012) reported that speed \& agility directly affects the skill of dribbling. Therefore dribbling had a positive relationship with speed and agility.According to Harald Dolles \& Sten Soderman (2005) made conclusions from their followup study they showed that players with good physical fitness had better ball dribbling technique during the match. The setting of today's football requires faster and faster players that would be unpredictable and elusive for the opponent. Speed as a basic motor ability is very important in the execution of technical elements in the football game (Milenkovuic, D., (2011).

\section{Conclusion}

Based on the research data, it can be concluded that:-

* Most of the players have very poor level of power performance, excellent level of speed and agility performance when we compared with the international standard of physical fitness level.

* Players who had average explosive leg power performance had good distance accurate shooting than those who had poor and very poor explosive leg power, players who had excellent and above average speed and agility performance had good speed dribbling technique in football than those who had average and below average speed and agility.

* Generally explosive leg power has their own effect on distance accuracy shooting and speed and agility has their own effect on speed dribbling.

\section{References}

1. Chapman S, DerseE, HansenJ. Soccer Coaching Manual. Los Angeles, USA: LA84 Foundation, 2007.

2. Dolles, H., and S. Söderman (2005a): Globalization of Sports - The Case of Professional Football and its International Management Challenges. DIJ Working Paper 05/1, Tokyo: German Institute for Japanese Studies.

3. Haghighi, A., M. Moghadasi, A.Nikseresht, A. Torkfar, and M.Haghighi. 2012. Effects of plyometric versus resistance training on sprint and skill performance in young soccer players. Eur J Exp Biol, 2:2348-2351. 
4. Hanafi Mahmoud Mokhtar (1994): Scientific foundations in football training, Dar ElFekr ElAraby. (In Arabic Language

5. Jukic I, Milanovic L, Sporis G and Vucetic V (2010) Reliability and factorial validity of agility tests for soccer players. Journal of Strength and Conditioning Research 24 (3) $679-687$

6. Milenković, D. (2011). Speed as an important component of football game. Acta Kinesiologica, 5(1), 57-61.

7. Pyne DB, Gardner A, Sheehan K, Hopkins W. Positional differences in tness and anthropometric characteristics in Australian football. J Sci Med Sport. 2006;9:143-150.PubMed doi:10.1016/j.jsams.2005.10.001

8. Reilly T., \& Williams M. (2003). Science and Soccer. New York: Routledge, USA.

9. Smajić, M., Molnar, S. (2007). Relations of Basic-Motoric Abilities and Specific Preciseness of Football Players of 10-12 Age. Journal for Sport, Physical Education and Health SPORT MONT, number 12, 13, 14 15, pg. 87-95. Podgorica.

10. Stolen, T., Chamari, K., Castagna,C.,\& Wisloff,U.(2005). Physiology of soccer ;An update. Sports medicine $36,(6), 501-536$.

11. Svensson M. and Drust B., "Testing soccer players," Journal of Sports Sciences, vol. 23, no. 6, pp. 601-618, 2005. 